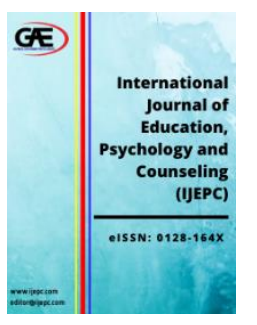

\author{
INTERNATIONAL JOURNAL OF \\ EDUCATION, PSYCHOLOGY \\ AND COUNSELLING \\ (IJEPC) \\ WWW.ijepc.com
}

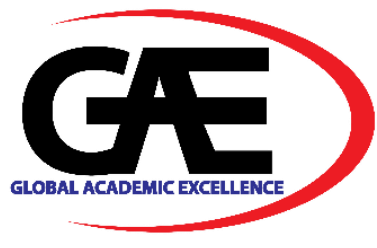

\title{
PENGARUH MEDIA SOSIAL TERHADAP PENAMPILAN AKHLAK
}

\section{THE INFLUENCE OF SOCIAL MEDIA ON STUDENT MORAL PERFORMANCE}

\author{
Mohd Fadhil Aziz ${ }^{1 *}$, Mardzelah Makhsin ${ }^{2 *}$ \\ 1 College of Arts and Sciences, Universiti Utara Malaysia, Malaysia \\ Email: fadhilkklk@gmail.com \\ 2 College of Arts and Sciences, Universiti Utara Malaysia, Malaysia \\ Email: mazfaniy@uum.edu.my \\ Corresponding Author
}

\begin{tabular}{l}
\hline Article Info: \\
Article history: \\
Received date: 06.06 .2021 \\
Revised date: 06.07 .2021 \\
Accepted date: 11.07 .2021 \\
Published date: 05.09 .2021 \\
To cite this document: \\
Aziz, M. F. \& Makhsin, M. (2021). \\
Pengaruh Media Sosial Terhadap \\
Penampilan Akhlak. International \\
Journal of Education, Psychology and \\
Counseling, 6 (42), 74-82.
\end{tabular}

DOI: $10.35631 /$ IJEPC.642007

This work is licensed under $\underline{\text { CC BY } 4.0}$ (c)

\begin{abstract}
Abstrak:
Kesan penggunaan media sosial terhadap tingkah laku dalam kalangan remaja pada zaman sekarang perlu diberi perhatian yang serius. Ramai remaja terpengaruh dengan paparan yang dikongsikan dalam media sosial dan menyebabkan timbulnya masalah tingkahlaku negatif di rumah atau di pusatpusat pengajian. Kewujudan masalah-masalah dalam kalangan remaja ini pasti ada faktor atau punca yang perlu di kenalpasti. Oleh itu kajian ini dilakukan bagi mengenalpasti tahap kekerapan penggunaan media sosial dan hubungannya dengan penampilan tingkah laku dalam kalangan pelajar kolej komnuniti dari segi pergaulan, komunikasi, berpakaian dan penghiburan. Media sosial dan kesannya terhadap remaja adalah isu yang sangat luas dan perlu dikaji secara mendalam sepanjang masa memandangkan perkembangannya dan kepesatannya sentiasa berlaku. Pengkaji hanya meberi fokus terhadap tiga jenis media sosial sahaja iaitu Facebook, Youtube dan Instagram. Kajian ini dilakukan secara kualitatif menggunakan kaedah kajian perpustakaan dengan membuat penelitian ke atas buku dan Jurnal. Dapatan yang telah di kenalpasti menunjukan terdapat banyak kebaikan dan keburukan media sosial terhadap remaja khususnya dalam aspek yang dikaji. Kajian ini sangat penting kerana ianya boleh menyedarkan pelajar bahawa media sosial boleh mempengaruhi akhlak yang negatif seterusnya membantu seluruh pendidik di semua peringkat memperbaiki sistem pengajaran mereka dengan menekankan elemen-elemen yang berkaitan bagi mengelakan masalah sosial negatif dalam kalangan pelajar lelaki dan perempuan.
\end{abstract}




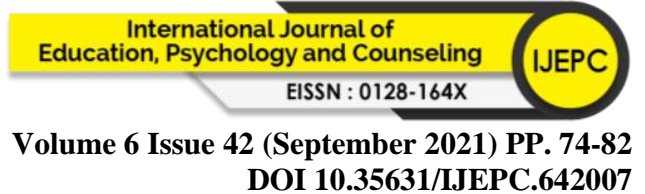

Kata Kunci:

Media Sosial, Akhlak, Pergaulan, Komuikasi, berpakaian, Penghiburan

Abstract:

The impact of social media use on behavior among Students of Higher Education institutions nowadays needs to be given serious attention. Many teenagers are influenced by the views shared on social media and cause the emergence of negative behavior problems at home or in educational institutions. The existence of these problems among teenagers is definitely a factor or cause that needs to be identified. Therefore, this study was conducted to identify the level of frequency of social media use and its relationship with the appearance of behavior among community college students in terms of socializing, communication, dressing, and entertainment. Social media and its impact on adolescents is a very broad issue and needs to be studied in depth all the time as its development and rapidity are always happening. The research only focused on three types of social media like Facebook, Youtube, and Instagram. This study was conducted qualitatively using the library research method by making research on books and journals. The findings that have been identified show that there are many advantages and disadvantages of social media for adolescents, especially in the aspects studied. This study is very important because it can make students aware that social media can influence negative morals and help all educators at all levels improve their teaching system by emphasizing the relevant elements to avoid negative social problems among male and female students.

Keywords:

Social Media, Morals, Socializing, Communication, Dressing, Entertainment

\section{Pengenalan}

Media sosial merupakan medium utama yang digunakan oleh seluruh masyarakat dalam kehidupan harian mereka. Media sosial ialah satu aplikasi berasaskan internet yang boleh dicapai menggunakan teknologi seperti komputer, tablet dan telefon pintar. Aplikasi ini membolehkan komuniti untuk berinteraksi dan berkongsi maklumat dengan komuniti lain (Lindsay, 2011). Perkembangan zaman yang pesat menyebabakan masyarakat terutamanya remaja pada masa kini berlumba untuk menggunakan media sosial seperti Facebook, Youtube, Twitter, Instagram dan sebagainya (Rosli et al., 2019). Menurut Hootsuite and We Are Social dalam laporan terkini Digital 2019, Pengguna internet meluangkan purata lapan jam lima minit sehari secara dalam talian dimana selama dua jam 59 minit digunakan oleh rakyat Malaysia untuk melayari media sosial (Sinar Harian 12 Mei 2019). Kewujudan media sosial membolehkan seseorang individu berinteraksi secara maya, mendapatkan berita terkini, maklumat serta perkongsian aktiviti sosial sama ada dari dalam dan luar negara. Media sosial juga boleh digunakan sebagai medium untuk mengisi masa lapang dalam berhibur dan turut memberi manfaat kepada sistem pendidikan masa kini. Memanfatkan media sosial memberikan pengaruh positif kepada pencapaian prestasi akademik pelajar iaitu pelajar bersemangat untuk belajar apabila dapat menggunakan media sosial untuk bertanya dan berbincang dengan guru atau rakan (Dina \& Siti, 2019). Media sosial sekarang bukan hanya sekadar menjadi medium bersosialisasi sahaja tetapi boleh digunakan dalam menyampaikan pelbagai informasi dan isu termasuk menyebarkan ilmu agama. (Muhammad et al., 2018; Muhammad \& Siti, 2019). Namun begitu, kecanggihan media sosial yang semakin rancak di 


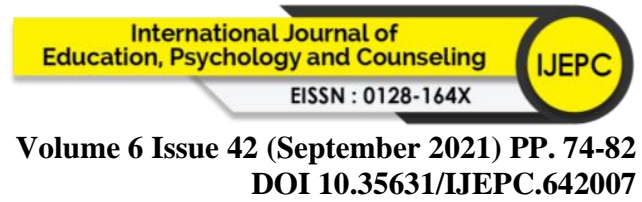

zaman sekarang telah memberikan implikasi yang besar terhadap semua lapisan masyarakat khususnya golongan pelajar Institut Pengajian Tinggi. Menurut Adam et. al. (2019) faktor yang menyebabkan kehancuran akhlak individu keluarga dan masyarakat ialah disebabkan tidak dapat mengimbangi aspek kerohanian dan fizikal dalam menggunakan teknologi. Kesan negatif terhadap penggunaan media sosial dalam kalangan pelajar apabila mereka lebih suka untuk melayari kandungan yang negatif dan ianya sukar untuk dibendung (Muhammad \& Hadi, 2020). Kajian yang dilakukan oleh Aprina (2017) jelas bahawa kekerapan yang tinggi dalam penggunaan media sosial memberi kesan terhadap akhlak mahasiswa sama ada positif atau negatif. Umat Islam sekarang sentiasa terdedah kepada maklumat yang palsu, tidak tepat, tidak senonoh yang boleh menyebabkan masyarakat kita semakin hilang jati diri dan keperibadian tingkah laku yang baik (Hamidah, 2005). Kebaikan dan keburukan sesuatu perkara pasti ada, khususnya dalam hal menggunakan media sosial, tetapi terpulang kepada individu yang menggunakannya membuat penialaian sendiri. Jadikanlah media sosial sebagai satu medium yang boleh memajukan diri dan berakhlak baik kerana pelbagai bentuk pengetahuan formal dan tidak formal boleh didapati dari media sosial (Aprina, 2017). Justeru, dapatan ini mendorong pengkaji untuk membuat kajian untuk melihat pengaruh penggunaan media sosial terhadap penampilan akhlak dari aspek pergaulan, komunikasi, pemakaian dan penghiburan dalam kalangan pelajar kolej komuniti.

\section{Kaedah Kajian}

Kajian ini dilakukan menerusi kajian perpustakaan dengan mengumpul data dari buku dan jurnal yang berkaitan. Pengkaji merujuk kepada buku-buku ilmiah bagi mendapat penjelasan daripada Ilmuan Islam terhadap maklumat berkaitan akhlak dan aspek-aspek yang terlibat. Seterusnya pengkaji membuat penelitian ke atas jurnal dengan memberi tumpuan khusus kepada kajian-kajian lepas yang membicarakan mengenai media sosial dan kesannya terhadap penampilan akhlak remaja masa kini.

\section{Media Sosial}

Media sosial menurut Kaplan dan Haelein (2010) sebuah medium aplikasi berasaskan jaringan internet yang diwujudkan dengan ideologi dan teknologi Web 2.0 dan yang membolehkan penciptaan dan pertukaran maklumat. Ia juga dikenali dengan sejenis peranti yang memerlukan data internet untuk membolehkan para pengguna berkongsi maklumat sama ada melalui blog, rangkaian sosial, wiki, forum, dunia virtual ke seluruh pelusuk dunia (Ahlqvist et al., 2008). Media merupakan sistem canggih yang semakin hari semakin maju aplikasi dan kemudahan yang ditawarkan (Normaliza, 2014). Sejak kebelakangan ini, media sosial telah menjadi aplikasi yang penting dalam menyebar maklumat dan berkomunikasi. Jeremy Cooper (2017) mendapati ramai pelajar memperoleh maklumat untuk membuat keputusan masuk ke universiti melali media sosial menunjukan bahawa golongan yang menggunakan kemudahan media sosial adalah ramai dari kalangan bakal pelajar Institut Pendidikan Tinggi. pengguna dapat menerima maklumat dan berkongsi idea serta dapat berinteraksi dengan seluruh masyarakat dunia (Kaplan \& Haelein (2010). Dalam hal ini, jelas menunjukan golongan pelajar di peringkat pengajian tinggi tidak terkecuali dalam menggunakan media sosial dalam kehidupan harian mereka.

\section{Media Sosial dan Kekerapan Penggunaan}

Cetinkaya et. al. (2014) penggunaan media sosial sangat tinggi dalam pelbagai aktiviti yang telah ditemui dalam kajiannya iaitu terhadap 160 responden terdiri daripada pelajar IPT. Khusnul dan Mohd. Helmi (2017) mendapati dalam kajiannya terhadap mahasiswa menunjukan keseluruhannya sering bergantung kepada media sosial seperti Facebook, Twitter, 


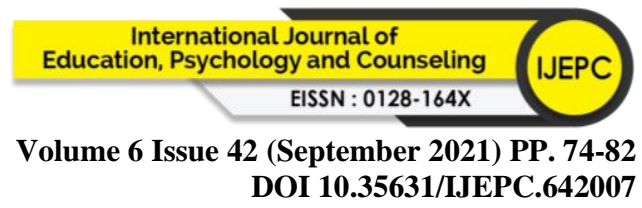

Instagram, aplikasi What app, Line, Youtube dan sebagainya. Menurut Ziani (2014) fungsi media sosial yang telah diperolehi dalam kajiannya iaitu, antaranya media sosial dijadikan sebagai alat untuk membantu seperti komunikasi dengan orang ramai, rakan, mahupun membantu dalam berkomunikasi dengan ahli-ahli kumpulan, digunakan sebagai medium untuk memindahkan maklumat di mana ia boleh dijadikan sebagai satu usaha untuk menyambung idea-idea dan mendapat matlamat iaitu memperolehi apa sahaja yang diinginkan. Fungsi yang telah dinyatakan menunjukan nedia sosial sering digunakan dalam memenuhi keperluan zaman sekarang. Selain itu, media sosial juga bukan hanya digunakan oleh golongan dewasa sahaja, kanak-kanak juga didapati mengambil masa selama lapan jam sehari menggunakan peralatan teknologi tersebut (Rosli et al., 2019).

Menurut Wan Norina et. al. (2018) Pelajar Politeknik Malaysia memilih Facebook sebagai akaun pilihan dalam aktiviti bersosial dimana mereka meluangkan masa yang lama menggunakannya. Perkara yang sama turut ditemui Mohd Zaidi dan Bahiyah (2013) hasil kajian mereka menunjukan semua pelajar universiti yang dijadikan responden dalam kajiannya iaitu seramai 400 orang menggunakan facebook. Maklumat yang telah dikeluarkan oleh Open Education pada awal tahun 2020 jumlah pemilik akaun bagi facebook ialah 24.9 juta orang, diikuti dengan pengguna instagram 12.7 juta orang. Kajian Mohd Zaidi dan Bahiyah, (2013) jumlah minimum penggunaan media sosial ialah selama 1 jam dan masa yang maksimum ialah 210 jam seminggu. Mohd Dahlan Dan Ida, (2010) mendapati remaja menghabiskan masa purata 4 jam sehari untuk melayari internet. Jamiah et. al. (2016) mendapati, secara purata remaja generasi $\mathrm{Z}$ yang dikaji menggunakan media sosial selama 11.6 jam sehari dan dan ada dikalangan responden yang mengakui menggunakan internet sepanjang hari iaitu selama 24 jam. Media sosial yang dimaksudkan termasuk semua yang disenaraikan oleh pengkaji iaitu Facebook, Youtube dan Instagram.

Aplikasi Youtube juga merupakan media sosial yang turut menjadi pilihan remaja masa kini. Youtube adalah sebuah laman yang boleh digunakan oleh pengguna secara percuma untuk memuat naik video dan boleh ditonton, dikongsi oleh semua orang (Carol, 2013). Menurut laman web rasmi Suruhanjaya komunikasi dan Multimedia Malaysia (2017) jumlah penggunaan keseluruhan media sosial ialah sebanyak 21.9 juta pada tahun 2016 dimana 97\% mengaku memiliki akaun Facebook, 56.1\% memiliki akaun Instagram dan Youtube berada di tempat ke tiga dengan jumlah 45.3\%. Bailey dan Ojelanki (2013) sebagai laman untuk pengguna memuat naik video, Youtube juga berfungsi untuk menghubungkan aplikasi rangkaian laman web seperti wiki, blog dan sebagainya.

Kekerapan penggunaan media sosial boleh diukur mengikut bilangan kenalan dan jumlah jam penggunaan dalam seminggu. Romlah (2019) seramai 70\% lebih responden mengaku sering media sosial melalui telefon pintar untuk berkomunikasi dan mengisi masa lapang. Mohd Effendi (2010) menyatakan bahwa 38\% pelajar kerap menggunakan laman Facebook iaitu 2 jam sehari, 56\% telah terlibat menggunakan Facebook selama tiga tahun dengan anggaran jumlah kenalan adalah seramai 201 hingga 300 orang rakan.

\section{Pengaruh Media Sosial Terhadap Akhlak}

Pengaruh media sosial terhadap tingkah laku telah dibuktikan oleh banyak pengkaji. Menurut Fazlinda dan Muhamad (2018) mendapati kebanyakan pelajar menyatakan terdapat banyak video yang tidak bermoral didedahkan di media sosial. Perkara ini perlu diambil berat kerana video yang tidak bermoral ini dapat merosakkan akhlak dan moral pelajar. Kajian Naquiah et. al. (2018) penggunaan teknologi secara berlebihan atau tidak terkawal akan menyebabkan kesan negatif kepada perkembangan fizikal dan otot, kemahiran interpersonal serta Copyright $\odot$ GLOBAL ACADEMIC EXCELLENCE (M) SDN BHD - All rights reserved 


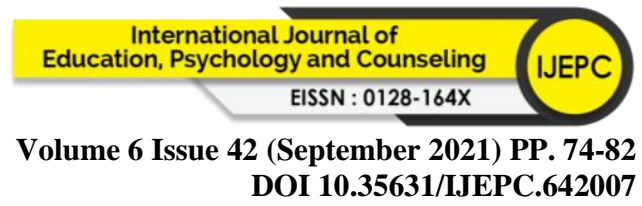

kemerosotan prestasi akademik terhadap golongan kanak-kanak dan remaja. penggunaan gajet dalam kalangan pelajar secara tidak terkawal, secara berlebihan ataupun gajet digunakan bagi tujuan yang tidak berfaedah akan mendorong kepada tingkah laku yang negatif dan boleh menjejaskan prestasi pelajar (Awang et al., 2016). kajian Ab. Halim dan Zarin (2009) mendapati tahap pendedahan yang tinggi terhadap media sosial, iaitu pelbagai teknologi media yang bertujuan untuk mencapai sejumlah besar pengguna media melalui komunikasi adalah faktor yang sangat mempengaruhi pegangan nilai akhlak remaja sehingga menyebabkan penularan masalah sosial. Tengku Elmi et. al. (2015) penglibatan remaja dalam pelbagai gejala sosial ini adalah berpunca daripada faktor dalaman diri remaja itu sendiri disebabkan banyak masa dihabiskan dengan media sosial. Zainudin dan Norazmah (2011), Azlina (2012) serta Zanariah et. al. (2016) Mendapati bahawa pelajar yang terlibat dengan masalah sosial ialah pelajar yang mempunyai keinginan yang tinggi untuk mencuba sesuatu yang baharu termasuk menggunakan aplikasi dalam media sosial yang tidak pernah mereka lakukan.

Zaharah (2013) menyatakan bahawa faktor media sosial telah mempengaruhi pembentukan akhlak remaja hari ini. Kajian oleh Wan Norina et.al. (2013) ke atas seramai 397 orang pelajar semester akhir peringkat diploma dari 10 buah Politeknik Malaysia, menunjukkan media sosial banyak memberi pengaruh positif kepada pelajar dan mereka masih lagi dapat memilih antara yang berfaedah mahupun sebaliknya. Namun begitu, terdapat segelintir daripada pelajar mengakui bahawa mereka juga turut terpengaruh dengan penampilan akhlak negatif hasil daripada bahan rancangan media dalam negara. Dapatan kajian oleh Syed Shah (2014) mendapati bahawa terdapat segelintir pengguna media sosial telah menyalahgunakan kemudahan komunikasi ini untuk mengekses internet dan laman yang tidak bermoral seperti web pornografi. Melalui kajian yang dilakukan oleh Azizi et. al. (2014) terhadap pelajar sekolah menengah di Johor mendapati bahawa filem atau cerita yang menayangkan aksi lasak dan agresif menjadi tarikan dan pilihan pelajar dimana ia boleh disaksikan secara percuma melalui laman sosial dan kesannya menyebabkan menularnya sikap dan tingkah laku agresif dalam kalangan remaja yang akhirnya menyebabkan banyak harta awam dirosakan dan berlakunya pergaduhan. Golongan muda yang menggunakan internet secara berlebihan sebenarnya mempunyai banyak masalah antaranya masalah dalam menjalinkan hubungan sosial, masalah sikap, masalah fizikal (Syed Shah et al., 2014). Khusnul dan Mohd. Helmi (2017) menyatakan media sosial merupakan faktor utama yang diperlukan sebagai ruang awam terbuka untuk menjalankan aktiviti berdemokrasi dan ia juga mempengaruhi dalam pembentukan gerakan sosial.

Jin (2013) menyatakan kesan penggunaan media sosial boleh mendatangkan kebaikan dan keburukan, walaubagaimanapun bergantung kepada cara penggunaaa, ciri personaliti dan sikap pengguna termasuklah kesediaan mereka untuk berkongsi maklumat dengan umum. Kajian yang dijalankan oleh Siti Zarina (2011) tentang implikasi remaja dalam melayari laman pornografi di internet mendapati golongan remaja melayu tidak berasa serba salah melayari laman pornografi dan kini menjadi salah satu budaya yang popular dalam kalangan mereka. Perkara seperti ini boleh berlaku disebabkan kebebasan dan kemudahan dalam media sosial yang sukar untuk dikawal. Hal ini dibuktikan dengan banyak dapatan kajian yang berkaitan menyatakan ciri media sosial yang terbuka dan tidak menghalang pengguna untuk berhibur menjadikan media sosial berkembang dengan cepat dan membuatkan aktiviti muat turun aplikasi laman sosial dalam telefon pintar pasti dilakukan. Abdul Halim et al., 2019; Hasbollah et al., 2019; Norazman et al., 2019; Haronzah et al., 2019, Rosli et al., 2019) 


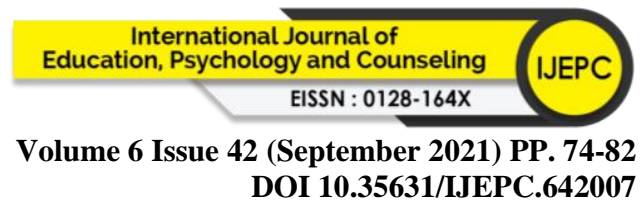

\section{Konsep Akhlak dan Kepentingannya Dalam Islam}

Pengertian akhlak menurut Abd al-Latif (1985) sifat atau prilaku yang timbul dari dalam jiwa seseorang dan dengan sifat tersebut akan menzahirkan perbuatan dengan mudah tanpa perlu berfikir ataupun di usahakan. Akhlak adalah sifat seseorang individu dari sejak lahir yang diperolehi menerusi latihan, ransangan yang boleh menjadi amalan kebiasaan dan ia meliputi dua bentuk iaitu dalaman dan luaran (Asmawati, 2009). Menurut Kamus Mu'jam Wajiz (2000) ilmu yang berkaitan dengan hukum nilai yang mempunyai hubungan dengan penampilan tingkahlaku sama ada baik atau buruk. Bugha (1997) sifat yang berada dalam diri seseorang, sama ada secara fitrah semula jadi maupun yang diusahakan dan boleh mempengaruhi sikap buruk dan baik (Harun, 2001; Imran, 2003; Asmawati, 2009). Akhlak juga merujuk kepada sikap yang menzahirkan tingkahlaku perbuatan manusia terhadap diri sendiri dan manusia lain menurut suruhan serta larangan dari al-Quran dan al-Hadis.

Akhlak menurut pandangan Islam merupakan elemen yang amat penting kepada umat manusia. Perkara ini terbukti apabila terdapat ayat Al-quran yang mengakui bahawa nabi dan rasul yang diutuskan merupakan contoh tauladan yang baik untuk di kuti oleh semua manusia. Hal ini dijelaskan oleh Allah SWT melalui surah al-Ahzab ayat 21 yang bermaksud: "Demi sesungguhnya, adalah bagi diri Rasulullah itu contoh ikutan yang baik". Selain itu, kepentingan akhlak juga dapat dilihat apabila antara tujuan utama perutusan baginda nabi Muhammad SAW. Oleh Allah SWT. adalah untuk menyempurnakan akhlak manusia. Sabda nabi yang di riwayatkan oleh al-Bukhari yang bermaksud: "Sesungguhnya aku diutuskan adalah untuk menyempurnakan akhlak yang mulia". Islam juga turut mementingkan keimanan dalam diri seseorang dan menyatakan antara orang yang benar-benar berjaya ialah mereka yang beriman. Menurut Mohd Nasir (2005) dalam al-Quran terdapat ayat yang berulang-ulang ungkapan yang bermaksud "kalangan orang yang beriman dan berbuat baik". Hal ini menunjukan, orang yang beriman hendaklah disokong dengan dengan perbuatan, tingkahlaku atau akhlak yang baik.

Kesimpulannya, mempunyai hubungan yang rapat dengan pengalaman, perbuatan dan latihan yang dilalui oleh manusia sama ada secara sedar atau tidak sedar. Pengalaman, perbuatan dan latihan yang baik akan mendorong atau menimbulkan akhlak yang baik dan ianya akan berlaku sebaliknya. Sifat dan persekitaran kehidupan yang baik akan membawa seseorang berakhlak dengan akhlak yang mulia dan sifat dan persekitaran kehidupan yang tidak baik akan menjadikan seseorang itu berakhlak dengan akhlak yang buruk. Tidak dapat dinafikan bahawa akhlak merupakan asas yang penting bagi semua manusia untuk menghayati dan menjiwainya dalam menjalani kehidupan didunia yang turut diambil kira dalam menentukan kejayaan di akhirat kelak.

\section{Akhlak Islam Dalam Pergaulan}

Pergaulan adalah jalinan perhubungan yang berlaku sesama manusia dalam menjalani kehidupan harian. Menurut Rokiah (1999) al-quran menggariskan beberapa kriteria kepada manusia dalam menalinkan hubungan seperti memberi salam apabila bertemu, kasih mengasihi, meminta izin kepada tuan empunya, menepati janji tolong-menolong dan menahan marah. Pergaulan boleh berlaku diantara adik beradik, ibu bapa, guru, jiran, rakan dan masyarakat. Islam tidak pernah melarang pergaulan sesama manusia, namun begitu ianya telah menetapkan peraturan yang terperinci dalam semua jenis peringkat manusia. Imam al-Ghazali (2012) Manusia mesti mengikut batas pergaulan yang ditetapkan iaitu hendaklah mengetahui batas pergaulan yang telah ditetapkan dalam Islam. Antara batas pergaulan yang perlu diberi perhatian ialah antara lelaki dan perempuan atau sesama jantina. Perkara ini bagi mengelakan 


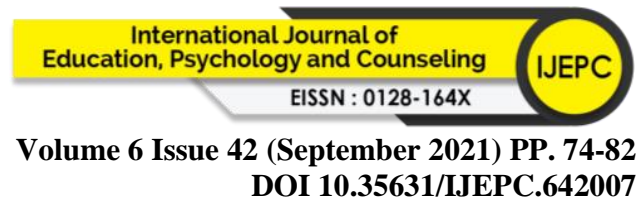

berlakunya pergaulan bebas yang boleh membawa kepada gejala sosial yang negatif seperti sumbang mahram dan perzinaan.

\section{Akhlak Islam Dalam Komunikasi}

Komunikasi menurut Byrnes (1975) dalam Abdul Almu'ati (2001) proses interaksi yang berlaku sesama manusia melibatkan pecakapan, perkongsian pendapat, gerak isyarat atau simbol mempunyai tujuan tertentu seperti mempengaruhi tingkah laku, keadaan fizikan dan mental manusia. Islam juga mempunyai panduan yang jelas dalam hal yang berkaitan komunikasi terhadap umatnya. Husin dan Mohd. Nasir (1997) mengikut akhlak yang dianjurkan dalam Islam, komunikasi adalah elemen dan cara penting dalam hubungan sosial dimana, elemen yang paling penting ialah berkaitan apa dan bagaimana cara untuk bertur kata serta berkongsi maklumat. Antara ciri-ciri komunikasi yang baik ialah jujur dengan apa yang ungkapkan, menggunakan bahasa yang sopan sama ada secara lisan, bahasa isyarat ataupun tulisan.

\section{Akhlak Islam Dalam Pakaian}

Pakaian merupakan satu keperluan asas kepada semua manusia dalam menjalani kehidupan di dunia ini. Terdapat pelbagai jenis pakaian mengikut agama dan budaya masing-masing. Dalam Islam, pakaian menjadi aspek penting dan diberi perhatian kerana ianya melibatkan halal serta haram dengan menggariskan beberapa ciri utama yang perlu ada. Menurut Lutfiah (2004) cara berpakaian yang melambangkan seseorang itu berakhlak dengan akhlak Islam ialah:

1. Pakaian yang longgar iaitu tidak ketat sehingga menampakan bentuk tubuh badan

2. Pakaian yang labuh menutup anggota aurat yang ditetapkan iaitu bagi wanita hendaklah melabuhkan tudung sehingga menutup bahagian dada.

3. Pakaian yang tidak telus pandangan iaitu jenis kain pakain tersebut hendaklah tidak nipis dan jarang sehingga boleh menampakan baying-bayang tubuh dan warna kulit pemakainya.

Beliau juga menjelaskan secara keseluruhannya bahawa pakaian yang berakhlak bagi lelaki hendaklah menutup dari atas pusat hingga ke bawah lutut manakala bagi perempuan pula hendaklah menutup keseluruhan tubuh kecuali muka dan dua tapak tangan. Hal ini adalah peraturan yang ditetapkan dalam al-Quaran dan al-Hadis. Selain itu, pakaian yang hendak dipakai juga tidak boleh menyerupai orang-orang yang ingkar kepada perintah agama seperti pakaian ahli gereja dan sebagainya.

\section{Akhlak Islam Dalam Penghiburan}

Hiburan adalah sesuatu yang boleh menghibur (menyukakan, menggembirakan) hati. Dewan bahasa dan pustaka, 2017). Hiburan bukan sekadar memberi kesronokan malah hiburan juga boleh digunakan sebagai medium untuk mendapatkan ilmu sambil berhibur (Hamzah et al., 2020). Jabatan Kemajuan Islam Malaysia dalam Muzakarah Jawatankuasa Majlis Fatwa (2015) telah mengeluarkan garis panduan dalam berhibur bagi memastikan aktiviti penghiburan terkawal dan mengikut syarak. Antara garis panduan tersebut ialah tidak membenarkan sebarang tayangan yang berunsur lucah, haram dan yang bertentangan dengan kepercayaan akidah Islam. Penonton tidak boleh terleka dengan hiburan sehingga melupakan kewajipan yang dituntut oleh syarak. Tidak boleh bercampur antara lelaki dan perempuan secara bebas apabila menghadiri program berbentuk hiburan yang dibenarkan. Peraturan ini amat penting bagi memastikan gejala-gejala yang melampau dapat dikurangkan dan tidak berulang lagi. Menurut Yusof (2015) budaya berhibur dalam kalangan remaja sudah pasti akan memberi kesan yang cukup besar. oleh yang demikian itu, sememangnya perkara ini perlu dipantau 


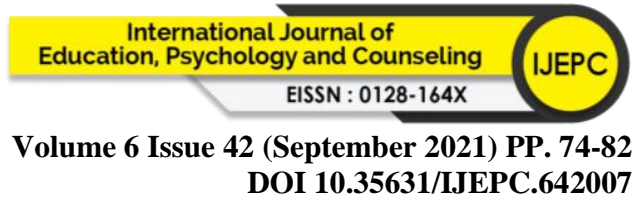

dengan sebaiknya agar ianya tidak samapai ke tahap yang lebih parah dan tindakan pencegahan awal adalah jalan yang sepatutnya dilakukan.

\section{Teori Pembelajaran Sosial}

Teori Pembelajaran Sosial telah diperkenalkan oleh Albert Bandura sangat sesuai dengan masalah yang berkaitan tingkah laku. Menurut Bandura (1997), Teori Pembelajaran Sosial (TPS) didefinisikan sebagai satu pembelajaran yang berlaku dengan memerhati orang lain melakukan sesuatu atau menjadikan seseorang sebagai model tingkah laku. Perkara ini bermaksud persekitaran dan juga orang-orang yang signifikan akan mempengaruhi tingkah laku. Bandura (1997) menyatakan seseorang individu akan memerhatikan sesuatu tingkah laku daripada orang lain yang signifikan dengannya dan menyimpan maklumat yang diperhatikan secara kognitif dan seterusnya mempersembahkan tingkah laku tersebut. Tingkah laku agresif pelajar dipelajari daripada persekitaran sosial seperti interaksi dengan keluarga, rakan sebaya, media sosial dan konsep kendiri individu (Mahmood, 2001). Perkara ini telah dikaji oleh Bandura (1997), mendapati kanak-kanak dan remaja banyak belajar melalui peniruan. Berdasarkan pembelajaran remaja melalui peniruan ini, maka remaja akan mengalami masalahmasalah sosial dimana mereka terjebak dengan unsur-unsur peniruan yang negatif seperti pergaulan bebas, menggunakan bahsa yang kurang sopan, berhibur dengan cara yang tidak sihat dan berpakaian yang tidak mengikut syariat. Segala-segalanya boleh didapati dari media sosial yang di ibaratkan seperti dunia tanpa sempadan.

\section{Akhlak dan Hubungan Dengan Teori Pembelajaran Sosial}

Berasaskan kepada sorotan kajian yang telah ditemui, ternyata teori ini amat sesuai digunakan dalam mengkaji akhlak pelajar terhadap penggunaan media sosial. Seperti yang telah dijelaskan dalam konsep akhlak, perkara ini jelas mempunyai persamaan diantara teori yang dipilih iaitu pengalaman akan mempengaruhi sesuatu tingkah laku yang baru dengan kekerapan penggunaan media sosial pelajar sebagai pengalaman yang akan mempengaruhi empat dimensi yang hendak dikaji. Dengan kata lain fungsi media sosial yang digunakan oleh pelajar sebagai alat untuk berintraksi dengan rakan-rakan yang tiada sekatan dan mendapatkan bahan-bahan yang tiada tapisan menyebabkan penyimpanan maklumat dan peniruan boleh berlaku. Justeru itu, dengan data-data dan teori yang diperolehi pengkaji yakin lebih yakin dalam menjalankan kajian berkaitan kekerapan pelajar menggunakan media sosial dengan akhlak pelajar dari segi komunikasi, pergaulan, berhibur dan berpakaian.

\section{Penutup}

Kesimpulannya, media sosial dan kesannya terhadap remaja adalah isu yang sangat luas dan perlu dikaji secara mendalam sepanjang masa memandangkan perkembangannya dan kepesatannya sentiasa berlaku. Dengan dapatan yang telah di kenalpasti menunjukan terdapat banyak kebaikan dan keburukan media sosial terhadap remaja. Walaubagaimanapun dapatan tersebut telah membantu pengkaji bagi memberi fokus sebenar terhadap kajian yang akan dilakukan. Setiap maklumat yang diperolehi tersebut akan dijadikan kayu ukur dalam kajian yang akan dilakukan sebagai usaha untuk menghasilkan kajian yang berkualiti dan boleh dimanfaatkan di kemudian hari.

\section{Rujukan}

Absha, A. A. B., \& Mohd. Isa, H. (2019). Faktor Keterlibatan Remaja Dengan Masalah Sosial. Jurnal Hadhari, 11(1), 1-17.

Al-Ghazali. (2012). Jadilah Orang Yang Menjiwai Iman Dan Hidayah.Selangor: Al-Hidayah House Of Publishers Sdn. Bhd. 


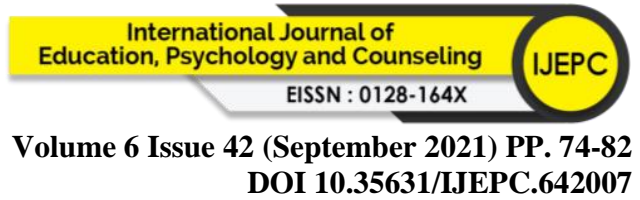

Aprina, C., \& Latifatul, K. (2017). Media Sosial dan Pengaruhnya Terhadap Akhlak Mahasiswa di Kota Metro. Jurnal Ath- Thariq 1(2), 55-66.

Awang, N. A. Ali, Normadiana, M. H., Mohd M. M. K., \& Sunardi, S. (2016). Kesan dan pengaruh gajet terhadap akhlak dan tingkah laku pelajar. Prosiding Konferensi Akademik, 1(2), 269-273.

Bandura, A. (1997). Self-efficacy: The exercise of control. W H Freeman/Time Books/ Henry Holt \& Co.

Cetinkaya. A, Sahin. O.E \& Kirik. A.M. 2014. A Research on Social and Political Use of Social Media in Turkey. International Journal of Sciences Culture and Sport, 2(4), 49-60.

Dina, D. S., \& Siti, W. (2019). Pemanfaatan Media Sosial Dalam Proses Pembelajaran di SMPN 1 Mojo Kediri. Indonesian Journal of Islamic Education Studies, 2(1), 50-60.

Fazlinda, A. H. \& Mohammad, S. M. M. (2018). Impak Media Sosial Terhadap Tingkah Laku Sosial Pelajar Di Kolej Vokasional. Online jurnal for TVET Practitioners 3(1), 27-37.

Hamidah, S. (2005). Pendidikan Islam dan Pengaruh Persekitaran dan Kemajuan: Kesan Kepada Pembentukan Sahsiah. Jurnal Masalah pendidikan, 1(1),71-77.

Ira, Maulin. O., Dewi, K. \& Eli, S. A. (2018). Pengaruh Bahasa Di Media Sosial Bagi Kalangan Remaja. Jurnal pendidikan bahasa dan sastera Indonesia 1(5), 114-126.

Jasmi, K. A. (2017). Remaja dan Kehidupan Berbatasan dalam Beragama. In Azmi Kamarul Jasmi (Ed.), Siri 4 Remaja Hebat: Batasan Dan Halangan Kecemerlangan Remaja Muslim. Skudai Johor: Penerbit UTM Press.

Mohd, Nasir. O. (2005). Akhlak dan Kaunseling Islam. Kuala Lumpur: Utusan Publications \& Distributors Sdn Bhd.

Muhammad, F., \& Hadi, M. (2020). Penggunaan Media Sosial di Kalangan Siswa Sekolah Dasar. Jurnal Pendidikan Dasar 4(1), 81-91.

Naquiah, N., Sahrunizam, S., Dharsigah, B. S., Nurhidayu, R., \& Abdul, H. A. (2018). Impak negatif teknologi moden dalam kehidupan dan perkembangan kanak-kanak hingga usia remaja. International Journal of Islamic and Civilizational Studies, 3(5), 187-199.

Wan Norina, W. H., Ahmad, F. M. Y., Zaharah, H. (2015). Hubungan Media Sosial Dengan Penampilan Akhlak Pelajar Politeknik Malaysia. Jurnal Teknikal \& Sains Sosial, 1(3), 68-81.

Wan Norina W. H., Zaharah, H., Ahmad F. M. Y., \& Ahmad A. S. (2013). Pengaruh Media Massa Terhadap Penampilan Akhlak Pelajar Islam Politeknik Malaysia. Jurnal O-jIE (The Online Journal Of Islamic Education), 1(1), 17-27.

Zainudin, S. \& Norazmah, M. R. (2011). Faktor-Faktor Yang Mempengaruhi Remaja Terlibat Dalam Masalah Sosial. Johor. Universiti Teknologi Mara. 